\title{
Fourier-transform infrared spectroscopic studies of dithia tetraphenylporphine
}

\author{
SANDEEP MISHRA, SARVPREET KAUR, S K TRIPATHI, C G MAHAJAN and \\ G S S SAINI* \\ Department of Physics, Panjab University, Chandigarh 160014 \\ e-mail: gsssaini@pu.ac.in
}

MS received 10 December 2005; revised 4 April 2006

\begin{abstract}
We present here infrared absorption spectra of dithia tetraphenylporphine and its cation in the 450-1600 and 2900-3400 $\mathrm{cm}^{-1}$ regions. Most of the allowed IR bands are observed in pairs due to overall $D_{2 h}$ point group symmetry of the molecule. The observed bands have been assigned to the porphyrin skeleton and phenyl ring modes. Some weak bands, which are forbidden under $D_{2 h}$, also appear in the spectra due to the distortion of the molecule from planarity-caused by the out-of-plane positioned $\mathrm{N}$ and $\mathrm{S}$ atoms. Increased intensity of some phenyl ring bands compared to free-base tetraphenylporphine is explained on the basis of rotation of phenyl rings towards the mean molecular plane. Contrary to the point group symmetry of cation of dithia tetraphenylporphine, certain bands are observed to be degenerate due to identical bonding arrangements in pyrrole rings of the cation.
\end{abstract}

Keywords. Infrared spectra, dithia tetraphenylporphine, dithia tetraphenylporphine cation.

\section{Introduction}

There is much current interest in the study of core modified porphyrins because of their interesting electronic properties and possible use as photosensitizer, catalyst and complexing agents. ${ }^{1-8}$ Coremodified porphyrinoid systems have been synthesized and studied to understand their electronic spectra, ${ }^{1,9}$ vibrational structure, ${ }^{10}$ electrochemical behaviour, ${ }^{11}$ aromatic character ${ }^{12}$ and complexing ability ${ }^{1,9}$ etc. Solid understanding of the structure and vibrations of the more complicated chalcogen porphyrins first requires good understanding of dithia tetraphenylporphine $\left(\mathrm{S}_{2} \mathrm{TPP}\right)$, which is one of the simplest coremodified tetraphenylporphine (TPP) macrocycles.

Vibrational spectroscopy provides rich and unique information about the bonding arrangement in a molecule in liquid or vapour state. Vibrations of a molecule can be probed by either Raman scattering technique or infrared (IR) absorption spectroscopy, which are complementary to each other. The Raman scattering under resonance condition has been utilized extensively in the study of vibrations of porphyrin molecules. On the other hand, IR absorption data are sparsely available on certain porphyrin molecules

\footnotetext{
*For correspondence
}

because of the fact that their IR spectra are crowded with large number of vibrational bands. Therefore, it is not an easy task to decipher information from the IR spectra of a macromolecule like TPP. Irrespective of these difficulties/shortcomings, IR spectroscopy has been used in the study of some TPPs and their oxidized products, ${ }^{13-17}$ since this technique is quite useful in arriving at the structure and bonding arrangements in these complexes. The $\mathrm{S}_{2} \mathrm{TPP}$ and its dication have been studied in the past and differences between neutral and cationic species are well characterized by resonance Raman (RR) spectroscopy. ${ }^{10,18}$ However, for complete vibrational analysis of the molecule, study of the Raman scattering and IR absorption both would be necessary. Moreover, we have not come across any IR absorption study on $\mathrm{S}_{2} \mathrm{TPP}$ except a brief mention of its spectrum in a limited region $1000-1150 \mathrm{~cm}^{-1} .{ }^{10}$ Therefore, in the present paper we report and analyse Fourier-transform infrared (FT-IR) spectra of $S_{2}$ TPP and its chemically prepared cation.

\section{Experimental}

Dithia tetraphenyl porphyrine was received from Professor A L Verma as a gift and used without further purification. However, its purity was checked 
with electronic absorption spectroscopy. $\mathrm{H}_{2} \mathrm{TPP}$ was obtained from Sigma. Benzene and $\mathrm{Br}_{2}$ from Qualigens Fine Chemicals, were also used without any purification. The cation of $\mathrm{S}_{2}$ TPP was prepared by adding trifluoroacetic acid or $\mathrm{Br}_{2}$ to $\mathrm{C}_{6} \mathrm{H}_{6}$ solution of $\mathrm{S}_{2}$ TPP. For recording of IR spectra, few drops of solution of $\mathrm{S}_{2} \mathrm{TPP}$ were put on a $\mathrm{KBr}$ window. Solvent was allowed to evaporate before taking the measurements in order to remove the IR absorption peaks of the solvent. Similar procedure was followed for IR measurements of cationic species. UV-visible spectra were recorded on a Hitachi 330 UV-Vis-NIR spectrophotometer. IR spectra were recorded on a Perkin-Elmer PE-Rx1 FTIR spectrophotometer. Spectral resolution of the IR spectrometer was $2 \mathrm{~cm}^{-1}$ throughout the experiment.

\section{Results and discussion}

Figure 1 gives the structure and atom-labeling scheme of $\mathrm{S}_{2}$ TPP. From UV-visible absorption spectroscopy, first of all the purity of $S_{2}$ TPP was checked. The observed bands (figure not shown) at $435 \mathrm{~nm}$ (Soret) and 512, 545, 632 and $695 \mathrm{~nm}$ ( $Q$ bands) match well with the reported values. ${ }^{19}$ The observed pattern of electronic absorption bands can be explained on the basis of overall $D_{2 h}$ molecular symmetry and structural change caused by the rotation of phenyl rings towards the porphyrin plane. Rotation of phenyl rings increases the interaction between porphine macrocycle and phenyl rings accompanied by much larger overlap between their $\pi$ systems. ${ }^{19}$

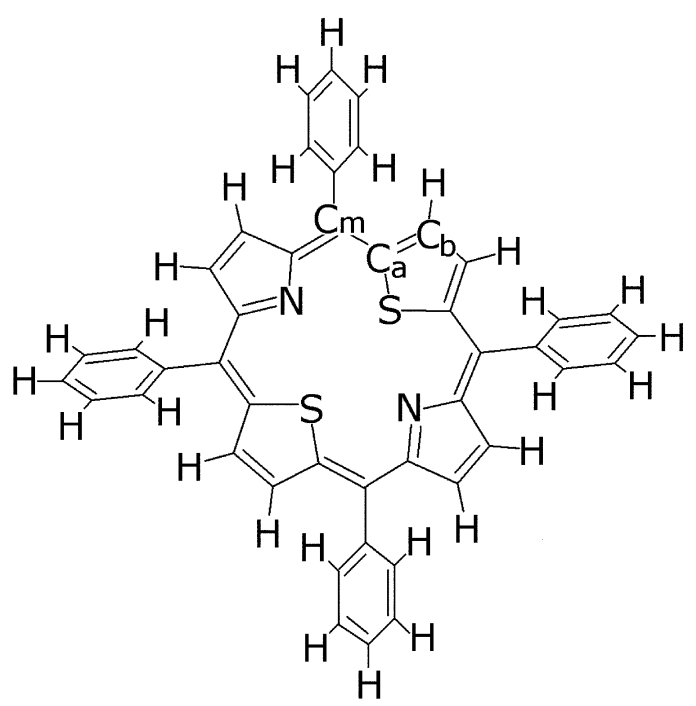

Figure 1. Structure and atom labelling scheme of dithia tetraphenylporphine.
IR spectra of $\mathrm{S}_{2} \mathrm{TPP}$ and its dication in different wave number regions are shown in figures 2-4. Spectra of $\mathrm{H}_{2} \mathrm{TPP}$ and its dication $\left(\mathrm{H}_{4} \mathrm{TPP}^{2+}\right)$ are also included for comparison. As can be seen from the figures, the spectra of $\mathrm{S}_{2}$ TPP contain more IR absorp-

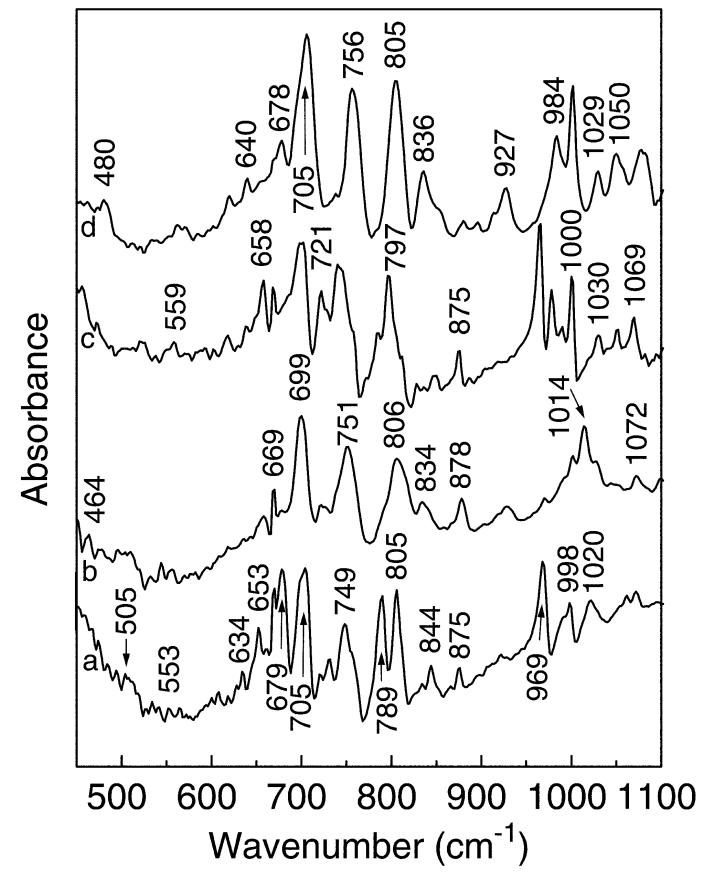

Figure 2. IR spectra of (a) $\mathrm{S}_{2} \mathrm{TPP}$; (b) $\mathrm{S}_{2} \mathrm{TPP}$ cation; (c) $\mathrm{H}_{2} \mathrm{TPP}$ and (d) $\mathrm{H}_{4} \mathrm{TPP}^{2+} 2 \mathrm{Br}^{-}$in the $450-1100 \mathrm{~cm}^{-1}$ region.

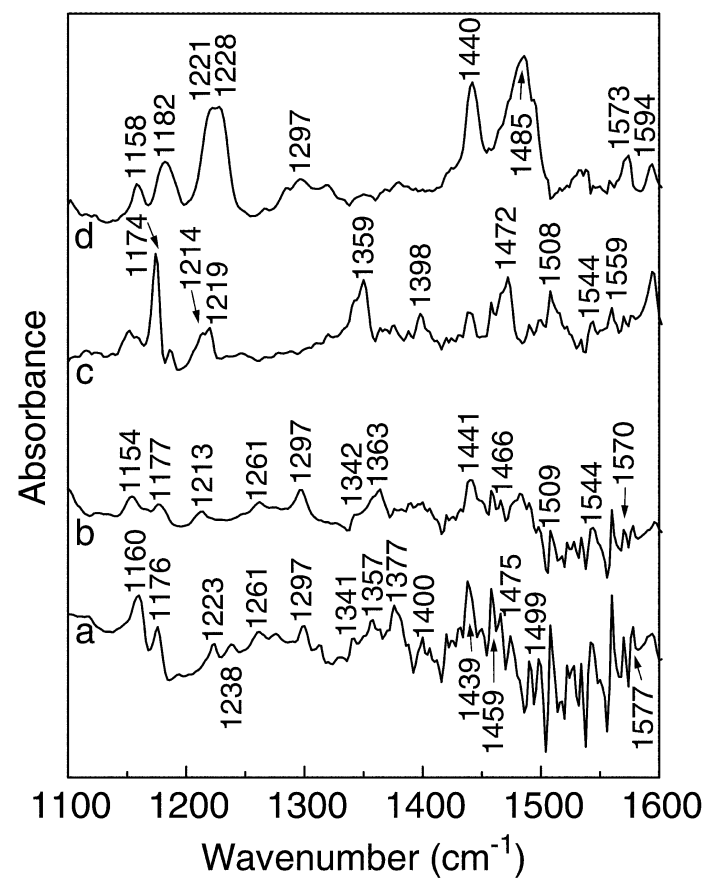

Figure 3. IR spectra of (a) $\mathrm{S}_{2} \mathrm{TPP}$; (b) $\mathrm{S}_{2} \mathrm{TPP}$ cation; (c) $\mathrm{H}_{2} \mathrm{TPP}$ and (d) $\mathrm{H}_{4} \mathrm{TPP}^{2+} 2 \mathrm{Br}^{-}$in the $1100-1600 \mathrm{~cm}^{-1}$ region. 


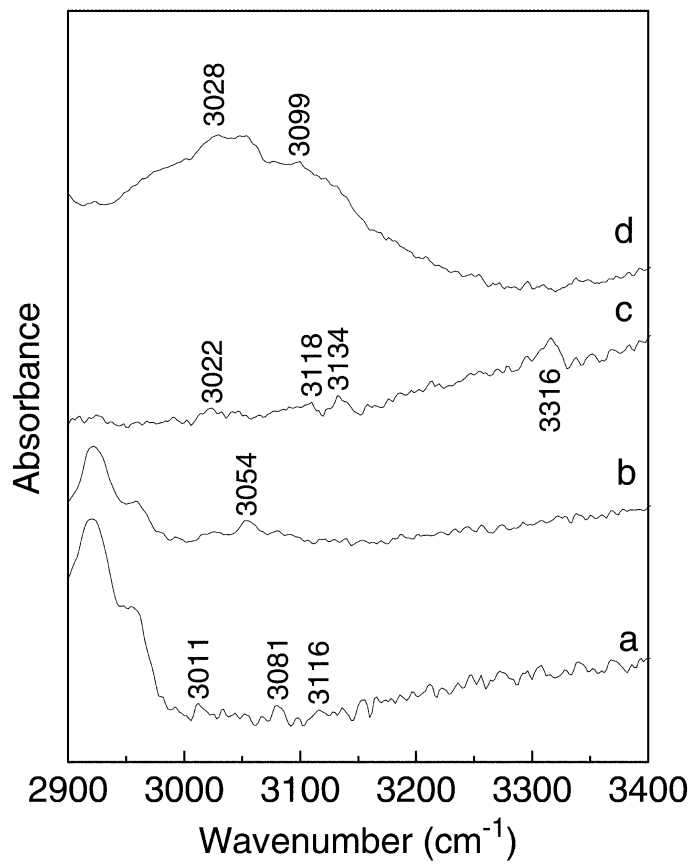

Figure 4. IR spectra of (a) $\mathrm{S}_{2} \mathrm{TPP}$; (b) $\mathrm{S}_{2} \mathrm{TPP}$ cation; (c) $\mathrm{H}_{2}$ TPP and (d) $\mathrm{H}_{4} \mathrm{TPP}^{2+} 2 \mathrm{Br}^{-}$in $2900-3400 \mathrm{~cm}^{-1}$ region.

tion bands than the $\mathrm{H}_{2}$ TPP spectra. Moreover, intensity patterns are also different. Some bands are also shifted with respect to the corresponding bands in $\mathrm{H}_{2}$ TPP. $\mathrm{S}_{2}$ TPP has two central $\mathrm{S}$ atoms on diagonally opposite pyrrole rings with an overall symmetry of $D_{2 h}$. Addition of two extra protons at two diagonally positioned $\mathrm{N}$ atoms results in the formation of dication of $\mathrm{S}_{2} \mathrm{TPP}$, which still maintains $D_{2 h}$ symmetry. Spectra of both these molecules consist of a few intense in-plane bands of $B_{2 u} / B_{3 u}$ symmetry and outof-plane bands of $B_{1 u}$ symmetry, which are allowed according to the selection rules of the $\mathrm{D}_{2 h}$ point group. These modes carry $A_{2 u}$ (out-of-plane vibration) and $E_{u}$ (in-plane vibration) symmetry label in $D_{4 h}$ point group, applicable in case of the metalloporphyrins. In $S_{2}$ TPP splitting of the $E_{u}$ modes into $B_{2 u}$ and $B_{3 u}$ symmetry modes can be interpreted in terms of point group symmetry of the molecule, because of the fact that there are two distinct pairs of pyrrole rings in $\mathrm{S}_{2} \mathrm{TPP}$. These two rings have different bond lengths and electron density. Therefore, corresponding to pyrrole ring with $\mathrm{N}$ atoms and $\mathrm{S}$ atoms, the $E_{u} \mathrm{sym}$ metry modes split into two species with different frequencies as can be seen in figures $2 \mathrm{a}$ and $3 \mathrm{a}$. A large number of weak bands, including the symmetry forbidden ones, which become allowed due to distortions in the molecule, can also be seen in the spectra of both $\mathrm{S}_{2} \mathrm{TPP}$ and its cation. The IR spectra contain more bands that can not be accounted for by the porphyrin skeleton. These bands might be due to overtones and combination modes. The assignment of the observed bands in the IR spectra is difficult because of its extreme complexity due to a large number of strong phenyl contributions. We have utilized a simpler, qualitative approach to interpret the IR data of $\mathrm{S}_{2} \mathrm{TPP}$ on the basis of mode compositions of $\mathrm{H}_{2}$ TPP and NiTPP. This is a reasonable approach in this case, since the data show that the modes retain the same general character in the $\mathrm{S}_{2} \mathrm{TPP}$ molecule as in other TPPs. Although normal coordinate calculations are not available for $\mathrm{S}_{2} \mathrm{TPP}$, they are available for $\mathrm{H}_{2} \mathrm{TPP},{ }^{16,20}$ free-base porphine $\left(\mathrm{H}_{2} \mathrm{P}\right),{ }^{21,22}$ nickel tetraphenylporphyrin (NiTPP) ${ }^{15}$ and free-base tetraphenylbacetriochlorin. ${ }^{23}$ These calculations along with the reported RR studies of these complexes ${ }^{10,18}$ and IR study of $\mathrm{H}_{2} \mathrm{TPP}^{14,17}$ considerably simplify the assignment of the IR bands of $S_{2}$ TPP. We have made suitable allowance for the difference in modes involving the two types of pyrrole rings. Changes with respect to spectra of other TPPs are also expected due to the altered masses apart from bonding effects. We expect that the mode compositions obtained in this way are reasonably accurate and that the major contributing motions are correct. The observed IR bands and their assignments are listed in table 1 . Throughout this discussion, the mode numbering from refs. ${ }^{15,21,22}$ is used for TPP with appropriate labeling for substituted and non-substituted pyrrole rings.

\subsection{Porphine skeleton modes}

3.1a Low wave number region: Figure 2 shows the IR spectra of $\mathrm{S}_{2} \mathrm{TPP}, \mathrm{H}_{2} \mathrm{TPP}$ and their cations in the wave number region $450-1100 \mathrm{~cm}^{-1}$. This region is generally dominated by bands due to ring torsion, ring rotation, and in-plane and out-of-plane bending modes of the porphyrin skeleton. We observe two well-isolated bands at 553 and $565 \mathrm{~cm}^{-1}$ in the spectrum of $\mathrm{S}_{2}$ TPP (figure 2a). The latter band disappears while the former shows slight upshift with concomitant increase in the width for cationic species (figure 2b). Appearance of two bands may be due to the substitution of $\mathrm{NH}$ atoms by $\mathrm{S}$ atoms. It may be mentioned here that only one band is reported for $\mathrm{H}_{2} \mathrm{TPP}$ around this wave number, which is assigned to $\mathrm{C}_{a}-\mathrm{C}_{m}$ bending motion. Disappearance of the band at $565 \mathrm{~cm}^{-1}$ suggests that the motion of the part of the molecule containing $\mathrm{N}$ atoms (with non-substituted pyrrole rings) is responsible for this band, while the 
Table 1. Position and assignment of observed IR bands of $S_{2} T P P$ and its cation in $\mathrm{C}_{6} \mathrm{H}_{6}$.

\begin{tabular}{|c|c|c|c|c|c|c|c|}
\hline \multicolumn{2}{|l|}{ Band $\left(\mathrm{cm}^{-1}\right)$} & \multirow[b]{2}{*}{ Mode no. ${ }^{1}$} & \multirow[b]{2}{*}{ Assignment $^{2-4}$} & \multicolumn{2}{|l|}{ Band $\left(\mathrm{cm}^{-1}\right)$} & \multirow[b]{2}{*}{ Mode no. ${ }^{1}$} & \multirow[b]{2}{*}{ Assignment $^{2-4}$} \\
\hline $\mathrm{S}_{2} \mathrm{TPP}$ neutral & $\mathrm{S}_{2} \mathrm{TPP}$ cation & & & $\mathrm{S}_{2} \mathrm{TPP}$ neutral & $\mathrm{S}_{2} \mathrm{TPP}$ cation & & \\
\hline 453 & 452 & $v_{33}, B_{1 g}$ & $\delta$ (Pyr rot) & 1062 & - & $v_{52 b}, B_{3 u}$ & $\delta\left(\mathrm{C}_{b}-\mathrm{H}\right)_{\mathrm{sym}}$ \\
\hline 460,468 & 464 & $v_{49}, B_{2 u} / B_{3 u}$ & $\delta$ (Pyr rot) & 1072 & 1072 & $v_{52 \mathrm{a}}, B_{2 u}$ & $\delta\left(\mathrm{C}_{\mathrm{b}}-\mathrm{H}\right)_{\mathrm{sym}}$ \\
\hline 475 & 476 & $\mathrm{v}_{25}, B_{1 g}$ & $\delta$ (Pyr rot) & 1117 & - & & \\
\hline 485 & - & & & 1126 & 1126 & & \\
\hline 495 & 496 & & Phenyl & 1136 & 1134 & & \\
\hline 505,508 & 504 & & Phenyl & 1151 & 1154 & $\psi_{7}, A_{u}$ & Phenyl \\
\hline 513 & 511 & $\pi_{5}^{\prime \prime}, B_{2 u} / B_{3 u}$ & Phenyl & 1160 & 1154 & $\psi_{7}^{\prime}, B_{1 u}$ & Phenyl \\
\hline 519,527 & 520 & & Phenyl & 1176,1193 & 1177 & $\phi_{6}^{\prime \prime}, B_{2 u} / B_{3 u}$ & Phenyl \\
\hline 534 & 532 & $\gamma_{13}, A_{u}$ & $\gamma\left(\mathrm{C}_{a}-\mathrm{C}_{m}\right)$ & 1201 & - & & \\
\hline 541 & 544 & & $\gamma\left(\mathrm{C}_{\mathrm{a}}-\mathrm{C}_{m}\right)$ & 1208 & - & & \\
\hline 553 & 556 & $\gamma_{7}, B_{1 u}$ & $\gamma\left(\mathrm{C}_{a}-\mathrm{C}_{m}\right)$ & 1223 & 1213 & $v_{51}, B_{2 u}$ & $\delta\left(\mathrm{C}_{b}-\mathrm{H}\right)_{\mathrm{asym}}$ \\
\hline 565 & - & & $\gamma_{7}\left(C_{a}-C_{m}\right)$ & 1238 & - & $v_{40 b}, B_{2 u}$ & v (Pyr quarter- \\
\hline 572 & 570 & & & & & & ring) \\
\hline 576,582 & 576,582 & $\gamma_{24}, B_{2 g} / B_{3 g}$ & $\gamma\left(\mathrm{C}_{a}-\mathrm{C}_{m}\right)$ & - & 1247 & $v_{27}, B_{1 g}$ & $v\left(\mathrm{C}_{m}\right.$-phenyl $)$ \\
\hline 607 & 608 & $v_{47 b} B_{3 u}$ & $\mathrm{v}$ (Pyr breath) & 1261 & 1261 & $v_{36}, B_{2 u} / B_{3 u}$ & $v\left(C_{m}\right.$-phenyl $)$ \\
\hline 618 & 618 & & Phenyl & 1275 & 1272 & $\psi_{6}^{\prime}, B_{1 u}$ & Phenyl \\
\hline 628 & - & & Phenyl & 1290 & - & $\psi_{6}^{\prime \prime}, B_{2 u} / B_{3 u}$ & Phenyl \\
\hline 635 & 636 & $\psi_{9}^{\prime}, B_{1 u}$ & Phenyl & 1297 & 1297 & $v_{40 a}, B_{3 u}$ & $v$ (Pyr quarter- \\
\hline 646 & 644 & $\gamma_{17}, B_{1 u}$ & $\gamma\left(\mathrm{C}_{b}-\mathrm{H}\right)_{\mathrm{sym}}$ & & & & ring) $)_{\text {sym }}$ \\
\hline 653,661 & 657 & $\gamma_{25}, B_{2 g} / B_{3 g}$ & $\gamma\left(\mathrm{C}_{b}-\mathrm{H}\right)_{\mathrm{sym}}$ & 1313 & 1363 & $\mathrm{v}_{41 b}, B_{3 u}$ & v (Pyr half- \\
\hline 669 & 669 & $\phi_{9}^{\prime \prime}, B_{2 u} / B_{3 u}$ & Phenyl & & & & ring $)_{\text {sym }}$ \\
\hline 679 & 677 & $\gamma_{1}, A_{u}$ & (Pyr fold $)_{\text {asym }}$ & 1320 & 1320 & $\psi_{5}^{\prime}, B_{1 u}$ & Phenyl \\
\hline- & 686 & & Phenyl & 1329 & 1328 & & Phenyl \\
\hline 699 & 699 & $\pi_{4}^{\prime \prime} B_{2 u} / B_{3 u}$ & Phenyl & 1341 & 1342 & & Phenyl \\
\hline 705 & 699 & $\gamma_{8}, B_{1 u}$ & $\gamma\left(C_{b}-\mathrm{H}\right)_{\mathrm{sym}}$ & 1357 & 1363 & $v_{41 a}, B_{2 u}$ & v (Pyr half- \\
\hline 721 & 722 & $\gamma_{20}, B_{2 g} / B_{3 g}$ & (Pyr fold) $)_{\text {asym }}$ & & & & ring $)_{\text {sym }}$ \\
\hline 731 & 727 & $\gamma_{11}, A_{u}$ & (Pyr fold) $)_{\text {asym }}$ & 1377 & 1377 & & $\mathrm{C}_{b}-\mathrm{H}$ bend \\
\hline 749,755 & 751 & $\pi_{3}^{\prime \prime}, B_{2 u} / B_{3 u}$ & Phenyl & 1380 & 1382 & & $\mathrm{C}_{b}-\mathrm{H}$ bend \\
\hline 789 & 791 & $\gamma_{15}, B_{1 u}$ & $(\text { Pyr fold })_{\text {sym }}$ & 1387 & 1389 & & $\mathrm{C}_{b}-\mathrm{H}$ bend \\
\hline 805 & 806 & $\gamma_{5}, B_{1 u}$ & (Pyr fold $)_{\text {sym }}$ & 1400 & 1400 & & $\mathrm{C}_{b}-\mathrm{H}$ bend \\
\hline 824 & - & $\mathrm{v}_{24}, B_{1 g}$ & (Pyr def) $)_{\text {asym }}$ & 1406 & 1406 & & $\mathrm{C}_{b}-\mathrm{H}$ bend \\
\hline 834 & 834 & $\mathrm{v}_{46 a}, B_{2 u}$ & $\delta(\text { Pyr def })_{\text {asym }}$ & 1421 & 1420 & & Phenyl \\
\hline 844 & - & $v_{46 b}, B_{3 u}$ & $\delta(\text { Pyr def })_{\text {asym }}+$ & 1425 & 1424 & & Phenyl \\
\hline & & & Phenyl & 1431 & 1432 & $\psi_{4}, A_{u}$ & Phenyl \\
\hline 865 & - & $\mathrm{v}_{48 b}, B_{3 u}$ & $\delta(\text { Pyr def })_{\mathrm{sym}}$ & 1439 & 1441 & $\psi_{4}^{\prime}, B_{1 u}$ & Phenyl \\
\hline 875 & 878 & $\gamma_{3}, A_{u}$ & $\delta\left(\mathrm{C}_{b}-\mathrm{H}\right)_{\text {asym }}$ & 1449 & 1449 & $\psi_{4}^{\prime \prime}, B_{2 \mathrm{~g}} / B_{3 g}$ & Phenyl \\
\hline 886 & - & $\gamma_{14}, A_{u}$ & $\delta\left(\mathrm{C}_{b}-\mathrm{H}\right)_{\text {asym }}$ & 1459 & 1459 & $v_{39 a}, B_{2 u}$ & $\mathrm{v}\left(\mathrm{C}_{a}-C_{m}\right)_{\text {in-phase }}$ \\
\hline 896 & 868 & $\mathrm{v}_{48 a}, B_{2 u}$ & $\delta(\text { Pyr def })_{\text {sym }}$ & 1466 & 1466 & $\mathrm{v}_{3}, A_{g}$ & $v\left(C_{a}-C_{m}\right)_{\text {in-phase }}$ \\
\hline 906 & 903 & & & 1475 & - & $v_{39 b}, B_{3 u}$ & $v\left(\mathrm{C}_{a}-C_{m}\right)_{\text {in-phase }}$ \\
\hline 912 & - & $\pi_{2}^{\prime \prime} B_{2 u} / B_{3 u}$ & Phenyl & 1482 & 1483 & $\mathrm{v}_{28}, B_{1 g}$ & $\mathrm{v}\left(\mathrm{C}_{a}-\mathrm{C}_{m}\right)_{\text {in-phase }}$ \\
\hline 921 & 919 & & Phenyl & 1491 & 1493 & $\phi_{5}^{\prime \prime}, B_{2 u} / B_{3 u}$ & Phenyl \\
\hline 929 & 928 & & Phenyl & 1499 & 1500 & & \\
\hline 937 & - & & Phenyl & 1509 & 1509 & $v_{38 \mathrm{a}}, B_{2 u}$ & $v\left(\mathrm{C}_{b}-\mathrm{C}_{b}\right)$ \\
\hline 945 & - & & Phenyl & 1523 & 1523 & $\mathrm{v}_{11}, A_{g}$ & $v\left(C_{b}-C_{b}\right)$ \\
\hline 952 & - & & Phenyl & 1527 & 1528 & $\mathrm{v}_{2}, A_{g}$ & $v\left(\mathrm{C}_{b}-\mathrm{C}_{b}\right)$ \\
\hline 969 & 970 & $v_{47 a}, B_{2 u}+$ & $\delta$ (Pyr breadth) & 1534 & 1535 & $v_{38 b}, B_{3 u}$ & $v\left(\mathrm{C}_{b}-\mathrm{C}_{b}\right)$ \\
\hline & & $\sigma_{1}^{\prime \prime}, B_{2 g} / B_{3 g}$ & + phenyl & 1542 & 1544 & $\mathrm{v}_{37 a}, B_{2 u}$ & $\mathrm{v}\left(\mathrm{C}_{a}-\mathrm{C}_{m}\right)_{\text {out-of-phase }}$ \\
\hline 991 & 992 & $v_{44 a}, B_{2 u}$ & v (Pyr half- & 1550 & 1550 & $\mathrm{v}_{19}, B_{1 g}$ & $v\left(\mathrm{C}_{a}-\mathrm{C}_{m}\right)$ \\
\hline & & & ring) $)_{\text {asym }}$ & 1560 & 1560 & $v_{37 b}, B_{3 u}$ & $v\left(\mathrm{C}_{a}-\mathrm{C}_{m}\right)_{\text {out-of-phase }}$ \\
\hline 998 & 1001 & $\phi_{8}^{\prime \prime}, B_{2 u} /_{B 3 u}$ & Phenyl & 1571 & 1570 & $\psi_{3 a}^{\prime \prime}$ & Phenyl \\
\hline 1020 & 1014 & $\mathrm{v}_{44 b}, B_{3 u}$ & V (Pyr half- & 1577 & 1577 & $\psi_{3 b}^{\prime \prime}$ & Phenyl \\
\hline & & & ring) $)_{\text {asym }}$ & 1591,1594 & 1591,1597 & $\phi_{4}^{\prime \prime}+\phi_{4}^{\prime}$ & Phenyl \\
\hline 1028 & 1028 & & Phenyl & - & - & - & \\
\hline 1053 & 1050 & $\psi_{8}^{\prime}, B_{1 u}$ & Phenyl & - & - & - & \\
\hline
\end{tabular}


Table 1. (Continued from facing page)

\begin{tabular}{|c|c|c|c|c|c|c|c|}
\hline \multicolumn{2}{|l|}{ Band $\left(\mathrm{cm}^{-1}\right)$} & \multirow[b]{2}{*}{ Mode no. ${ }^{1}$} & \multirow[b]{2}{*}{ Assignment $^{2-4}$} & \multicolumn{2}{|l|}{ Band $\left(\mathrm{cm}^{-1}\right)$} & \multirow[b]{2}{*}{ Mode no. ${ }^{1}$} & \multirow[b]{2}{*}{ Assignment $^{2-4}$} \\
\hline $\mathrm{S}_{2} \mathrm{TPP}$ neutral & $\mathrm{S}_{2} \mathrm{TPP}$ cation & & & $\mathrm{S}_{2} \mathrm{TPP}$ neutral & $\mathrm{S}_{2} \mathrm{TPP}$ cation & & \\
\hline 3011 & 3014 & $\phi_{3 a}^{\prime \prime}$ & Phenyl & 3081 & 3080 & $v_{43}, B_{2 u} / B_{3 u}$ & $\mathrm{v}\left(\mathrm{C}_{b}-\mathrm{H}\right)_{\mathrm{sym}}$ \\
\hline 3022 & 3022 & $\phi_{3 b}^{\prime \prime}$ & Phenyl & 3116 & 3117 & $v_{45}, B_{2 u} / B_{3 u}$ & $v\left(\mathrm{C}_{b}-\mathrm{H}\right)_{\mathrm{asym}}$ \\
\hline- & 3054 & & Phenyl & - & 3308 & & $v(\mathrm{~N}-\mathrm{H})$ \\
\hline
\end{tabular}

${ }^{1}$ Mode numbering and symmetry are based on ref. [22]

${ }^{2}$ Assignments are based on references [15, 21, 22]

The $v, \delta, \gamma$ denote stretching, in-plane bending and out-of-plane bending modes respectively. The subscript sym and asym represent the symmetric and asymmetric modes respectively

${ }^{4} \pi, \phi$ and $\psi$ denote phenyl ring vibrations

former band is due to the substituted pyrrole rings, since on cation formation, $\mathrm{H}$ atoms are added to the pyrrole rings containing $\mathrm{N}$ atoms, thereby affecting the vibrations of only the ring with $\mathrm{N}$ atoms. In the spectra of $\mathrm{S}_{2} \mathrm{TPP}$ and its cation, bands due to pyrrole fold motion can be seen at 679,721 and $731 \mathrm{~cm}^{-1}$. The lower wave number band is assigned to the $\gamma_{1}$ mode of $A_{u}$ symmetry. The band due to this mode in $\mathrm{H}_{4} \mathrm{TPP}^{2+}$ has also been reported at the same frequency. ${ }^{17}$ Assignment of this band gets support from the fact that electrochemical data reported in the literature $^{24}$ also indicate similarity in properties of $\mathrm{S}_{2} \mathrm{TPP}$ and $\mathrm{H}_{4} \mathrm{TPP}^{2+}$. Interestingly, the band due to this mode is absent in the spectrum of $\mathrm{H}_{2}$ TPP but present in $\mathrm{H}_{4} \mathrm{TPP}^{2+}$, however, the reverse is true for $\mathrm{S}_{2} \mathrm{TPP}$ and its cation with the only difference that its intensity is not completely diminished for the $S_{2}$ TPP cation. Since $\gamma_{1}$ is a symmetry-allowed vibration under $D_{4 h}, D_{2 h}$ point groups and their sub groups, it should have also been present with reasonable intensity in the spectrum of cationic $S_{2}$ TPP. However, its intensity is considerably reduced on cation formation. The reduction in the intensity may be explained, if we consider mixing between this mode and other modes with the same symmetry and similar eigenvectors. The mixing leads to negligible or complete cancellation of intensity of one band while the intensity of the other band increases due to phasing. This situation is similar to metallo-TPPs in which mixing of eigenvectors of $v_{2}$ and $v_{3}$ modes is responsible for reduced intensity of the RR band assigned to $v_{3} .{ }^{25}$ We feel that the $\gamma_{1}$ mode, for which $\mathrm{C}_{b}$ and $\mathrm{C}_{a}$ atoms move out of phase, may mix with the $\mathrm{C}_{b}$-H asymmetric bending mode $\gamma_{3}$, which also has $A_{u}$ symmetry. Due to this mixing, the intensity for the former mode is nearly cancelled due to phasing while for the latter the intensity increases. The $\gamma_{3}$ mode is present at
$875 \mathrm{~cm}^{-1}$ in the IR spectrum of $S_{2}$ TPP cation with relatively increased intensity compared to $S_{2}$ TPP.

A pair of well-resolved bands with strong intensity can be seen at 789 and $805 \mathrm{~cm}^{-1}$ in the spectrum of $S_{2}$ TPP (figure 2a). On cation formation, the lower wave number band almost disappears while the higher wave number band remains unchanged. These bands may be assigned to symmetric pyrrole-folding modes $\gamma_{15}$ and $\gamma_{5}$ respectively with contribution from the $\mathrm{C}_{b}-\mathrm{H}$ bending. This assignment is based on the latest DFT-based normal coordinate analysis of $\mathrm{H}_{2}$ TPP and NiTPP. ${ }^{15,16,20}$ The $\gamma_{5}$ mode is predicted to have a large out-of-plane component of dipole moment due to large in-phase out-of-plane displacement of the $\mathrm{C}_{b}-\mathrm{H}$ atoms. Hence, the latter intense band is assigned to $\gamma_{5}$. A band at $799 \mathrm{~cm}^{-1}$ in $\mathrm{H}_{2}$ TPP is assigned to $\mathrm{N}-\mathrm{H}$ out-of-plane bending motion in a recent study. ${ }^{16}$ However, we observe a band at $805 \mathrm{~cm}^{-1}$ even in the IR spectrum of $S_{2}$ TPP. If this band is due to $\mathrm{N}-\mathrm{H}$ bending, then it should not be present in the spectrum of $\mathrm{S}_{2}$ TPP until the molecule is oxidized by addition of protons. Hence, this mode does not arise due to $\mathrm{N}-\mathrm{H}$ bending in $\mathrm{S}_{2}$ TPP. Therefore, assignment of this band to $\gamma_{5}$ mode is justified by the above discussion and is in agreement with the IR band at $794 \mathrm{~cm}^{-1}$ in NiTPP assigned to $\gamma_{5}$ mode by Rush et $a l^{15}$. A band at $824 \mathrm{~cm}^{-1}$ may be assigned to asymmetric pyrrole deformation mode $v_{24}$ of $B_{1 g}$ symmetry. Similarly, a doublet at 834 and $844 \mathrm{~cm}^{-1}$ may also arise due to asymmetric pyrrole deformation motion and accordingly we have assigned them to $v_{46 a}$ and $v_{46 b}$ respectively of $B_{2 u} / \mathrm{B}_{3 u}$ symmetry. On cation formation, these bands can be seen at $834 \mathrm{~cm}^{-1}$ in the IR spectrum (figure 2b). Symmetric pyrrole deformation modes $v_{48 a}$ and $v_{48 b}$ give rise to IR bands at 865 and $896 \mathrm{~cm}^{-1}$. Since these modes involve movement of $\mathrm{N}$ and/or $\mathrm{S}$ atoms, in the spec- 
trum vibrational frequency of a band should be lower for the pyrrole rings with $\mathrm{S}$ atoms and, therefore, the former band is assigned to $v_{48}$ mode with contribution from the S-substituted pyrrole rings and the latter from non-substituted pyrrole rings. On cation formation, $\mathrm{H}$ atoms are attached to the $\mathrm{N}$ atoms of the pyrrole rings. It is observed for $\mathrm{H}_{2}$ TPP that the electron density on the $\mathrm{N}$ atoms decreases due to dication formation. ${ }^{26}$ If we assume a similar situation for $S_{2}$ TPP, then the latter band should shift downward for cationic $S_{2} T P P$, while the former may show either no shift or very small shift in its position. Based on this argument, we assign a band (shoulder) at $868 \mathrm{~cm}^{-1}$ to symmetric pyrrole deformation mode $v_{48}$ for $S_{2}$ TPP cations.

We may assign bands at 969 and $607 \mathrm{~cm}^{-1}$ to pyrrole breathing modes $v_{47 a}\left(B_{2 u}\right)$ and $v_{47 b}\left(B_{3 u}\right)$ respectively. Stein $e t a l^{9}$ have assigned a band at $630 \mathrm{~cm}^{-1}$ in the RR spectra of $\mathrm{S}_{2}$ TPP to $\mathrm{C}_{a}$-S stretching, which arises due to pyrrole breathing stretching mode $v_{6}$. Corresponding IR active band involving pyrrole breathing mode is $v_{47}$. It is observed in X-ray structure analysis ${ }^{19}$ and molecular orbital calculations ${ }^{27}$ that replacement of $\mathrm{NH}$ groups by $\mathrm{S}$ atoms drains electron density from the porphyrin ring and also $\mathrm{S}$ atoms are known to take part in direct bonding interactions within the porphyrin core. NMR studies also show changes in the inner and outer aromatic pathways of the core due to bonding interaction between $\mathrm{S}$ atoms and the ring. ${ }^{28}$ Since $\mathrm{S}$ atoms change the inner ring aromaticity more than the outer pathway, bonding between the inner bonds is affected more than the bonds at the outer periphery of the ring. One, therefore, expects that the vibrational frequencies of the molecule involving the inner atoms such as $\mathrm{C}_{a}$ will change more than the frequencies of the vibration related to $\mathrm{C}_{b}$ atoms. We, therefore, assign $607 \mathrm{~cm}^{-1}$ band to $v_{47 b}$ mode involving contribution from $\mathrm{C}_{a}-\mathrm{S}$. Moreover, on cation formation, there should not be any apparent change in $\mathrm{C}_{a}-\mathrm{S}$ stretching frequency as protons are attached to $\mathrm{N}$ atoms. In the spectrum of $S_{2}$ TPP cation (figure $2 b$ ), position of $607 \mathrm{~cm}^{-1}$ is changed by only $1 \mathrm{~cm}^{-1}$. Therefore, small change in the wave number of the band due to cation formation also justifies the assignment of this band. As can be seen from figure $2 \mathrm{a}$ and $b$, intensity of this band decreases on cation formation, which indicates change in the molecular symmetry due to change in planarity of the molecule. The pair of bands at 991 and $1020 \mathrm{~cm}^{-1}$ may be assigned to asymmetric pyrrole half-ring stretching vibrational modes $v_{44 a, b}$. These bands shift to $1014 \mathrm{~cm}^{-1}$ for cationic species. The doublet at 1062 and $1072 \mathrm{~cm}^{-1}$ may be assigned to $v_{52 a, b}$ modes of $B_{2 u} / B_{3 u}$ symmetry due to in-plane $\mathrm{C}_{b}-\mathrm{H}$ symmetric bending vibration. These bands are observed at $1072 \mathrm{~cm}^{-1}$ in the spectra of the cationic species.

3.2b Mid-wave number region: In the wave number region $1100-1600 \mathrm{~cm}^{-1}$, generally, bands associated with the symmetric and asymmetric $\mathrm{C}_{a}-\mathrm{C}_{m}, \mathrm{C}_{b}-\mathrm{C}_{b}$, pyrrole quarter-ring and pyrrole symmetric and asymmetric half-ring stretching modes are observed. In the IR spectrum of $S_{2}$ TPP (figure $3 a$ ), only one band is observed around $1223 \mathrm{~cm}^{-1}$ in comparison with the doublet observed at 1214 and $1219 \mathrm{~cm}^{-1}$ for $\mathrm{H}_{2}$ TPP (figure 3c). The $1223 \mathrm{~cm}^{-1}$ band may be assigned to asymmetric in-plane $\mathrm{C}_{b}-\mathrm{H}$ bending vibrational mode $v_{51}$. The other band at low wave number is absent in the $\mathrm{S}_{2} \mathrm{TPP}$ spectrum. The lower wave number band in $\mathrm{H}_{2}$ TPP is assigned to $\mathrm{N}-\mathrm{H}$ bending motion. This observation is consistent with the fact that the $\mathrm{S}_{2} \mathrm{TPP}$ molecule does not have an $\mathrm{NH}$ group. Accordingly, we observe only a single band at $1223 \mathrm{~cm}^{-1}$, which shifts down to $1213 \mathrm{~cm}^{-1}$ for cationic $\mathrm{S}_{2} \mathrm{TPP}$. This shift is in agreement with the shift in other $\mathrm{C}_{b}-\mathrm{H}$ related vibrations. The downshift can be explained on the basis of reduced electron density on $\mathrm{C}_{b}$ and $\mathrm{H}$ atoms attached to $\mathrm{C}_{b}$ as seen in $\mathrm{H}_{4} \mathrm{TPP}^{2+}$ from NMR spectroscopy by Inisan $e t a l^{26}$. The $\mathrm{C}_{m}$-phenyl vibrational mode, $v_{36}$, remains at its position on cation formation and is observed at $1261 \mathrm{~cm}^{-1}$ in the spectra of both $\mathrm{S}_{2}$ TPP and its cation. IR bands at 1298 and $1238 \mathrm{~cm}^{-1}$ may be assigned to $v_{40 a}$ and $v_{40 b}$ modes respectively. The local coordinate giving rise to these bands is the pyrrole quarter ring stretching vibration. The calculated position of doubly degenerate $v_{40}$ mode by Rush et al ${ }^{15}$ is $1312 \mathrm{~cm}^{-1}$ for NiTPP using DFT technique. However, by empirical normal coordinate analysis method, its positions are calculated at $1408 \mathrm{~cm}^{-1}\left(\mathrm{v}_{40 a}\right)$ and $1402 \mathrm{~cm}^{-1}\left(\mathrm{v}_{40 b}\right)$ for free-base porphine ${ }^{22}$ and at $1382 \mathrm{~cm}^{-1}\left(\mathrm{v}_{40 a}\right)$ and $1227 \mathrm{~cm}^{-1}\left(v_{40 b}\right)$ for free-base tetraphenylbacteriochlorin. ${ }^{23}$ Porphyrin ring-related stretching vibrations in $S_{2}$ TPP show downshift with respect to the corresponding bands in $\mathrm{H}_{2}$ TPP. ${ }^{10} \mathrm{We}$ have, therefore, assigned the 1297 and $1238 \mathrm{~cm}^{-1}$ bands to $V_{40 a, b}$ modes due to quarter-ring stretching of substituted and non-substituted pyrrole respectively. Pyrrole quarter-ring stretching motion is coupled to $\mathrm{C}_{b}-\mathrm{H}$ bending according to DFT calculation of porphine by Kozlowski et $a l^{21}$. These authors have calculated 
bands at $1252 \mathrm{~cm}^{-1}$ of $B_{2 u}$ symmetry due to $\mathrm{C}_{b}-\mathrm{H}$ deformation with $\mathrm{C}_{a}-\mathrm{N}$ and $\mathrm{C}_{a}-\mathrm{C}_{b}$ stretching and at $1408 \mathrm{~cm}^{-1}$ of $B_{3 u}$ symmetry due to $\mathrm{C}_{a}-\mathrm{N}$ and $\mathrm{C}_{a}-\mathrm{C}_{b}$ stretching. Also in a recent IR study of $\mathrm{H}_{2} \mathrm{TPP}$, a band at $1249 \mathrm{~cm}^{-1}$ has been assigned to $\mathrm{C}_{a}-\mathrm{N}$ stretching mode. ${ }^{14}$ This further justifies assignment of 1297 and $1238 \mathrm{~cm}^{-1}$ bands to $v_{40 a, b}$ modes. In $\mathrm{S}_{2}$ TPP cation only a single band at $1297 \mathrm{~cm}^{-1}$ is observed corresponding to these bands. A weak band at $1247 \mathrm{~cm}^{-1}$ is also assigned to forbidden IR mode $v_{27}$. Symmetric pyrrole half-ring stretching modes $v_{41 b}\left(B_{3 u}\right)$ and $v_{41 a}\left(B_{2 u}\right)$ are observed at 1313 and $1357 \mathrm{~cm}^{-1}$ for non-substituted and substituted pyrrole rings respectively in the IR spectrum of neutral compound (figure $3 \mathrm{a}$ ). These bands shift to new position at $1363 \mathrm{~cm}^{-1}$ in cation spectrum. However, observation of weak bands at $1357 \mathrm{~cm}^{-1}$ in figure $3 \mathrm{~b}$ shows the presence of small amount, of non-oxidized $\mathrm{S}_{2} \mathrm{TPP}$. As can be seen from the IR spectra of oxidized $\mathrm{S}_{2} \mathrm{TPP}$, all the molecules are not converted to cationic form, since some bands at $1357 \mathrm{~cm}^{-1}$ and between 1500 and $1600 \mathrm{~cm}^{-1}$ can still be seen at the positions of the neutral species with non-zero intensity. It suggests that dithia porphyrins are difficult to oxidize compared to free-base porphyrins. In fact, from the electrochemical studies of $S_{2}$ TPP, it was found that the oxidation potential of this molecule is more positive compared to $\mathrm{H}_{2} \mathrm{TPP}^{24}$ The symmetric pyrrole half-ring stretching mode can be described by the out-of-plane $\mathrm{C}_{a}-\mathrm{N} / \mathrm{C}_{a}-\mathrm{S}$ and $\mathrm{C}_{a}-\mathrm{C}_{b}$ stretching in opposite pyrrole rings. The out-of-phase stretching motion of $\mathrm{C}_{a}-\mathrm{S}$ and $\mathrm{C}_{a}-\mathrm{C}_{b}$ also leads to marked change in the $\mathrm{C}_{a}-\mathrm{C}_{m}-\mathrm{C}_{a}$ angle. This in turn causes rather large amplitude in the motion of the $\mathrm{C}_{m}$-phenyl bond. Hence, the intensity of the band assigned to $\mathrm{C}_{m}$-phenyl in $\mathrm{S}_{2}$ TPP is more than the intensity of the corresponding band in $\mathrm{H}_{2}$ TPP. Bands at 1377 , $1411 \mathrm{~cm}^{-1}$ and other bands within these wave number position may be assigned to $\mathrm{C}-\mathrm{H}$ bending of the porphyrin ring in accordance with recently reported studies. ${ }^{20}$

Bands in the wave number region beyond $1450 \mathrm{~cm}^{-1}$ arise mainly due to $\mathrm{C}_{a}-\mathrm{C}_{m}, \mathrm{C}_{b}-\mathrm{C}_{b}$ and phenyl ring stretching vibrations. Doublets at 1459 and $1475 \mathrm{~cm}^{-1}$ bands in $\mathrm{S}_{2}$ TPP may be assigned to $\mathrm{V}_{39 a, b}$ modes having in-phase $\mathrm{C}_{a}-\mathrm{C}_{m}$ motion. Weak intensity bands at 1466 and $1482 \mathrm{~cm}^{-1}$ bands may be assigned to forbidden modes $v_{3}\left(A_{g}\right)$ and $v_{28}\left(B_{1 g}\right)$ modes respectively. These modes also involve in-phase motion of the $\mathrm{C}_{a}-\mathrm{C}_{m}$ vibration. Other bands, which may also be assigned to $\mathrm{C}_{a}-\mathrm{C}_{m}$ vibrational modes $\mathrm{V}_{37 a, b}\left(B_{2 u} / B_{3 u}\right)$ and forbidden $v_{19}\left(B_{1 g}\right)$, are observed at 1542, 1560 and $1550 \mathrm{~cm}^{-1}$ respectively. In metalloporphyrins with $D_{4 h}$ symmetry, the $\mathrm{C}_{a}-\mathrm{C}_{m}$ modes are grouped into two categories according to whether they are symmetric or asymmetric with respect to the $C_{2^{\prime}}$ axis passing through the opposite meso carbon atoms. In $\mathrm{S}_{2} \mathrm{TPP}$ and its cation as well as $\mathrm{H}_{2} \mathrm{TPP}$, the $C_{2^{\prime}}$ axis is lost due to redution of the molecular symmetry to $D_{2 h}$. Therefore, according to $\mathrm{Li}$ and Zgierski, ${ }^{22}$ it is more appropriate to use in-phase and out-of-phase combination of the two adjacent $\mathrm{C}_{a}-\mathrm{C}_{m}$ stretching instead of symmetric and asymmetric respectively to describe these modes. In the spectrum of $\mathrm{S}_{2} \mathrm{TPP}$, bands due to $\mathrm{C}_{b}-\mathrm{C}_{b}$ stretching have been observed at 1509 , 1534 and 1523 and $1527 \mathrm{~cm}^{-1}$ and assigned to $v_{38 a, b}$ $\left(B_{2 u} / B_{3 u}\right), v_{11}\left(A_{g}\right)$ and $v_{2}\left(A_{g}\right)$ modes respectively. Of these modes, the latter two are forbidden under $D_{2 h}$ symmetry. As can be seen from Figures 2-4, intensity patterns and vibrational frequencies of different IR bands in the spectra of $\mathrm{S}_{2} \mathrm{TPP}$ are quite similar to the spectra of the dication of $\mathrm{H}_{2}$ TPP. Similarity in the spectra may be due to the similarity between their structures, although they belong to different point groups. The point group symmetry of $\mathrm{H}_{4} \mathrm{TPP}^{2+}$ is $\mathrm{S}_{4}$. Both are known to have considerable nonplanarity. ${ }^{19,24}$ According to the X-ray measurements, ${ }^{19}$ the $\mathrm{S}$ atoms are displaced out of the porphyrin plane by 0.09 and the $\mathrm{N}$ atoms by 0.24 in $\mathrm{S}{ }_{2} \mathrm{TPP}$. Nonplanarity is, therefore, responsible for the appearance of the bands which are otherwise forbidden under ideal $D_{2 h}$ symmetry. The effective symmetry of this molecule in reality may be taken as $\mathrm{C}_{2 v}$, which is less than the assumed symmetry $D_{2 h}$.

3.1c High wave number region: The $\mathrm{N}-\mathrm{H}$ stretching bands observed at 3316 and $3310 \mathrm{~cm}^{-1}$ in $\mathrm{H}_{2}$ TPP and its dication respectively (figure 4) are no longer seen in the spectrum of $S_{2}$ TPP. This observation is in complete agreement with the structure of the molecule, which does not have an $\mathrm{N}-\mathrm{H}$ bond. Dications of $\mathrm{S}_{2} \mathrm{TPP}$, prepared by adding trifluoroacetic acid to the solution, have shown this band at $3308 \mathrm{~cm}^{-1}$ with reduced intensity. Similar observations, have been made in case of $\mathrm{H}_{2}$ TPP. However, the number of $\mathrm{N}-\mathrm{H}$ bonds are just half in the cation of $\mathrm{S}_{2} \mathrm{TPP}$ compared to $\mathrm{H}_{4} \mathrm{TPP}^{2+}$. Therefore, intensity of the band in the former compound is still weaker than in the latter. Reduction of the intensity on dication formation also indicates that the derivative of the transition dipole moment with respect to $\mathrm{N}-\mathrm{H}$ stretching mode also becomes very small. Other bands observed in the 
higher wave number region are due to the stretching vibrational motion of $\mathrm{C}_{b}-\mathrm{H}$ bond of the porphyrin ring and $\mathrm{C}-\mathrm{H}$ stretching of phenyl rings. Spectrum of $\mathrm{S}_{2}$ TPP shows bands due to $\mathrm{C}_{b}-\mathrm{H}$ stretching modes at 3081 and $3116 \mathrm{~cm}^{-1}$ with shoulders and other weak bands. It seems that the above bands correspond to 3108 and $3134 \mathrm{~cm}^{-1}$ bands of $\mathrm{H}_{2} \mathrm{TPP}$ (figure $4 \mathrm{a}, \mathrm{c}$ ). The downshift in the wave numbers of these bands for $\mathrm{S}_{2} \mathrm{TPP}$ compared to $\mathrm{H}_{2} \mathrm{TPP}$ indicates the weakening of $\mathrm{C}_{b}-\mathrm{H}$ bonds of the former compound. This observation gets support from earlier reported work on this molecule. ${ }^{24}$

\subsection{Phenyl ring modes}

A number of phenyl ring modes are observed in the IR spectra of $\mathrm{S}_{2} \mathrm{TPP}$, similar to $\mathrm{H}_{2} \mathrm{TPP}$. Modes internal to the phenyl rings are expected to occur at essentially the same frequencies as in other TPPs. Although steric hindrance between the ortho hydrogen atoms of the phenyl groups and the adjacent pyrrole rings opposes the rotation of phenyl group in the porphyrin plane in ground state, yet most phenyl ring modes are mixed with porphyrin ring modes through the phasing of their eigenvectors.

The band at $669 \mathrm{~cm}^{-1}$ does not show any change in its position and intensity on cation formation. Hence, this band may be assigned to the in-plane phenyl ring vibrational mode $\phi_{9}^{\prime \prime}$. Other bands, which may arise due to phenyl ring stretching are observed at 749 and $755 \mathrm{~cm}^{-1}$ and can be assigned to $\pi_{3 a, b}^{\prime \prime}$ modes respectively. In the spectrum of cationic species only one band is seen at $751 \mathrm{~cm}^{-1}$ corresponding to $\pi_{3 a, b}^{\prime \prime}$. The $844 \mathrm{~cm}^{-1}$ band may have contribution from the phenyl ring according to Zhang et al ${ }^{16}$, therefore, this band is also assigned to phenyl ring vibration. A number of weak bands at $912,952 \mathrm{~cm}^{-1}$ and between these wave number positions may also be assigned to phenyl ring vibrations. The 1151 and $1160 \mathrm{~cm}^{-1}$ bands are due to out-of-plane phenyl ring vibrational modes $\psi_{7}$ and $\psi_{7^{\prime}}^{\prime}$ of $A_{u}$ and $B_{1 u}$ symmetry respectively. These are seen at $1154 \mathrm{~cm}^{-1}$ for dication. Bands at 1431,1439 and $1449 \mathrm{~cm}^{-1}$ may be assigned to phenyl ring modes $\psi_{4}\left(A_{u}\right), \psi_{4}^{\prime}\left(B_{1 u}\right)$ and $\psi_{4}^{\prime \prime}\left(B_{2 g} / B_{3 g}\right)$ respectively. These bands also do not show any shift on cation formation. As can be seen, IR bands related to phenyl rings are more intense in $\mathrm{S}_{2} \mathrm{TPP}$ spectra than in $\mathrm{H}_{2} \mathrm{TPP}$. This indicates orientational change of the phenyl rings with respect to the porphyrin plane in the former molecule in comparison with the latter. Orientational change is a result of the structural change caused by the presence of the $\mathrm{S}$ atoms as discussed above. X-ray and electronic absorption spectroscopy ${ }^{19}$ also suggest rotation of phenyl rings in $\mathrm{S}_{2} \mathrm{TPP}$ towards the mean porphyrin plane, which is accompanied by much larger overlap between their $\pi$ systems.

As mentioned above, the $E_{u}$ symmetry modes in the spectra of $\mathrm{S}_{2}$ TPP split into $B_{2 u}$ and $B_{3 u}$ species due to its point group symmetry $D_{2 h}$ similar to $\mathrm{H}_{2}$ TPP. However, contrary to its point group symmetry, certain porphyrin ring as well as phenyl ring related bands in the spectra of $S_{2}$ TPP cation are degenerate as in $\mathrm{H}_{4} \mathrm{TPP}^{2+}$. There is one fundamental difference in the degeneracy of these bands in these molecules. In $\mathrm{H}_{2}$ TPP, the symmetry of the molecule increases from two-fold to four-fold $\left(\mathrm{S}_{4}\right)$ due to addition of protons at the $\mathrm{N}$ atoms of the deprotonated pyrrole rings on cation formation. Thus in case of $\mathrm{H}_{4} \mathrm{TPP}^{2+}$, not only is the point group symmetry of the molecule increased but the pyrrole rings are also similar to each other in every respect as far as bonding arrangements and force constants are concerned. Similar to $\mathrm{H}_{4} \mathrm{TPP}^{2+}$, two protons attach to $\mathrm{N}$ atoms of non-substituted pyrrole rings on formation of $\mathrm{S}_{2} \mathrm{TPP}$ cation. Thus, effective point group symmetry of the molecule is still two-fold even after addition of two protons. Therefore, the degeneracy of IR bands cannot be explained only on the basis of point group symmetry. In $\mathrm{H}_{4} \mathrm{TPP}^{2+}$, extra protons attached to the $\mathrm{N}$ atoms of pyrrole rings reduce electron density on the pyrrole rings. ${ }^{26}$ Addition of protons in case of $\mathrm{S}_{2} \mathrm{TPP}$ may also have similar effect on the electron density on pyrrole rings. We can, therefore, assume that the electron density on the pyrrole rings with $\mathrm{N}$ atoms is reduced on oxidation (protonation). On the other hand, electron density on the substituted pyrrole rings is already reduced by the $\mathrm{S}$ atoms. Thus, the net effect of the protonation of the molecule is the reduction of electron density on the nonsubstituted pyrrole rings to an extent that it becomes nearly equal to the electron density on the substituted pyrrole rings, thereby making the two types of pyrrole ring equivalent in terms of electron density, bond order and force constants. Hence, some of the vibrations are accidently degenerate in the spectra of $\mathrm{S}_{2} \mathrm{TPP}$ cation, contrary to the point group symmetry.

In the high wave number region, some bands can be identified with the phenyl ring vibrations. Bands at 3011 and $3022 \mathrm{~cm}^{-1}$ either remain at their respective positions or change their position by a few wave numbers with reduced intensity for cations. On the 
other hand, phenyl C-H stretching band at $3054 \mathrm{~cm}^{-1}$, which does not have detectable intensity for neutral species, gains intensity in the cation spectrum (figure $4 \mathrm{~b})$. These observations indicate that the bonding arrangements in phenyl rings of $S_{2}$ TPP and its cation are almost identical, but orientation is different as already mentioned above.

\section{Conclusions}

From the above discussion, it is clear that the observed IR bands of $S_{2}$ TPP can be assigned, in general, on the basis of overall $D_{2 h}$ symmetry of the molecule. Reduction in symmetry, due to small outof-plane displacement of $\mathrm{N}$ and $\mathrm{S}$ atoms is responsible for non-zero intensity of forbidden bands under $D_{2 h}$ point group. Further from the analysis of the spectra of $\mathrm{S}_{2} \mathrm{TPP}$ cation, it can be concluded that two types of pyrrole rings in cationic species are identical in bonding arragements.

\section{Acknowledgment}

We thank Professor A L Verma of the North Eastern Hill University, Shillong for providing us the dithia tetraphenylporphine. Spectra were recorded at the Regional Sophisticated Instrumentation Centre, Panjab University, Chandigarh. S K thanks the Council of Scientific and Industrial Research (CSIR) for a fellowship SRA. Financial assistance from CSIR is gratefully acknowledged.

\section{References}

1. Misra R, Anand V G, Rath H and Chandrashekar T K 2005 J. Chem. Sci. 11799

2. Gupta I and Ravikanth M 2005 J. Chem. Sci. 117 161

3. Punnagai M, Joseph S and Sastry G N 2004 J. Chem.. Sci. 116271

4. Parmeswaran D, Pushpan S K, Srinivasan A, Kumar M R, Chandrashekaran T K and Ganesan S 2003 Photochem. Photobiol. 78487

5. Srinivasan A, Kumar M R, Pandian R P, Mahajan S, Pushpan K S, Sridevi B, Narayanan S J and Chandra- shekar T K 1999 J. Porphyrins Phthalocyanines 2 305

6. Gupta I, Hung C-H and Ravikanth M 2003 Eur. J. Org. Chem. 20034392

7. Agarwal N, Hung C-H and Ravikanth M 2003 Eur. J. Org. Chem. 20033730

8. Santra S, Kumaresan D, Agarwal N and Ravikanth M 2003 Tetrahedron $\mathbf{5 9} 2353$

9. Stein P, Ulman A and Spiro 1984 J. Phys. Chem. 88369

10. Pandian R P, Reddy D, Chidambaram N and Chandrashekar T K 1990 Proc. Indian Acad. Sci. Chem. Sci. 102307

11. Vogel E, Rohrig P, Sicken M, Knipp B, Harrmann A, Pohl M, Schinickler H and Lex J 1989 Angew. Chem 281651

12. Grazynski L L, Lisowski L, Olmstead M M and Balch A L 1989 Inorg. Chem. 281183

13. Hu S and Spiro T G 1993 J. Am. Chem. Soc. 115 12029

14. Zhang Y-H, Chen D-M, He T and Liu F-C 2003 Spectrochim. Acta $\mathbf{A 5 9} 87$

15. Rush III T S, Kozlowski P M, Piffat C A, Kumble R, Zgierski M Z and Spiro T G 2000 J. Phys. Chem. B104 5020

16. Zhang Y-H, Ruan W-J, Li Z-Y, Wu Y and Zheng J-Y 2005 Chem. Phys. 315201

17. Saini G S S, Sharma S, Kaur S, Tripathi S K and Mahajan C G 2005 Spectrochim. Acta A61 3070

18. Pandian R P, Chandrashekar T K, Saini G S S and Verma A L 1993 J. Chem. Soc. Faraday Trans. 89677

19. Ulman A and Manassen J 1975 J. Am. Chem. Soc. 97 6540

20. Bour P, Zaruba K, Urbanova M, Setnicka V, Matejka P, Fiedler Z, Kral V and Volka K 2000 Chirality 12 191

21. Kozlowski P M, Jarzecki A A, Pulay P, Li X-Y and Zgierski M Z 1996 J. Phys. Chem. 10013985

22. Li X-Y and Zgierski M Z 1991 J. Phys. Chem. 95 4268

23. Lin C-Y and Spiro T G 1997 J. Phys. Chem. 101472

24. Ulman A, Manassen J, Frolow F and Rabinovich D 1981 Inorg. Chem. 201987

25. Li X-Y, Czernuszewicz R S, Kincaid J R, Su Y O and Spiro T G 1990 J. Phys. Chem. 9431

26. Inisan C, Saillard J Y, Guilard R, Tabard A and Mest Y L 1998 New J. Chem. 823

27. Hill R, Gouterman M and Ulman A 1982 Inorg. Chem. 211450

28. Ulman A, Manassen J, Frolow F and Rabinovich D 1979 J. Am. Chem. Soc. 1017055

29. Stone A and Fleischer E B 1968 J. Am. Chem. Soc. 902735. 